\title{
Código dos direitos e deveres da pessoa hospitalizada no SUS: o cotidiano hospitalar na roda de conversa
}

\author{
Annatália Meneses de Amorim Gomes ${ }^{1}$ \\ José Jackson Coelho Sampaio² \\ Maria das Graças Barreto de Carvalho ${ }^{3}$ \\ Marilyn Kay Nations ${ }^{4}$ \\ Maria Socorro Costa Feitosa Alves ${ }^{5}$
}

GOMES, A.M.A. et al. Code of rights and obligations of hospitalized patients within the Brazilian National Health System (SUS): the daily hospital routine under discussion.

Interface - Comunic., Saúde, Educ., v.12, n.27, p.773-82, out./dez. 2008.

Patients' rights constitute a mechanism for changing the care and management within the Brazilian National Health System (SUS). The aim of this study was to present round-table discussions about the rights and obligations of SUS patients within the hospital environment. This was a descriptive, exploratory study, conducted at two hospitals in Fortaleza, Ceará. Three round-table discussions were held at each institution, involving 40 staff members from various professions and sectors. The debate was on the text of the Code of Rights and Obligations of SUS Patients in Ceará. The discourse was analyzed in accordance with the content analysis method of Lawrence Bardin. It was perceived that the consolidated rules made it difficult to put the rights into practice, and the roundtable discussion broadened this critical view through its insight. This was shown to be an important educational instrument for citizens' rights and for humanization of the healthcare process.

Key words: Patients' rights. Humanization of assistance. Health education.
Os direitos dos pacientes consistem em dispositivo para mudar a atenção e a gestão no Sistema Único de Saúde - SUS. O objetivo deste trabalho é apresentar as rodas de conversa sobre os direitos e deveres dos usuários do SUS no âmbito das unidades hospitalares. Trata-se de um estudo descritivo e exploratório, realizado em dois hospitais de Fortaleza, Ceará. Foram promovidas, em cada serviço, três rodas de conversa com 40 trabalhadores de várias profissões e setores. Utilizou-se para o debate o texto do Código de Direitos e Deveres do Paciente no SUS/ CE. Os discursos foram analisados segundo a Análise de Conteúdo, consoante Lawrence Bardin. Percebeu-se que normas consolidadas dificultam a efetivação dos direitos, e a roda de conversa ampliou a visão crítica, promovendo discernimento. Esta se revelou importante instrumento de educação para a cidadania e humanização do processo de cuidado.

Palavras-chave: Direitos do paciente. Humanização da assistência. Educação em saúde.

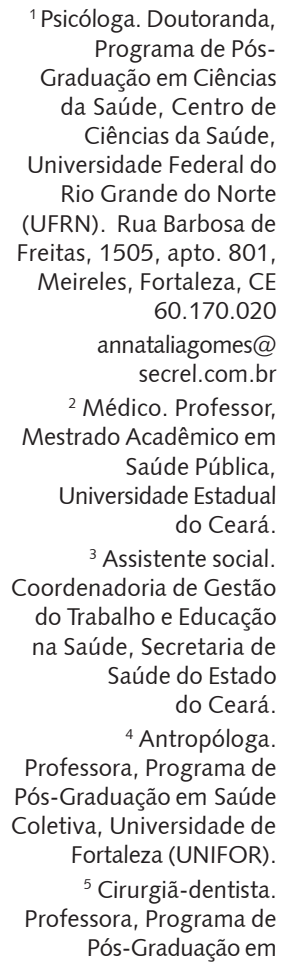

${ }^{1}$ Psicóloga. Doutoranda, Programa de PósGraduação em Ciências da Saúde, Centro de Ciências da Saúde,

Universidade Federal do Rio Grande do Norte (UFRN). Rua Barbosa de Freitas, 1505, apto. 801, Meireles, Fortaleza, CE 60.170 .020 annataliagomes@ secrel.com.br

${ }^{2}$ Médico. Professor, Mestrado Acadêmico em Saúde Pública,

Universidade Estadual do Ceará.

${ }^{3}$ Assistente social.

Coordenadoria de Gestão do Trabalho e Educação na Saúde, Secretaria de Saúde do Estado do Ceará. ${ }^{4}$ Antropóloga.

Professora, Programa de Pós-Graduação em Saúde Coletiva, Universidade de Fortaleza (UNIFOR).

${ }^{5}$ Cirurgiã-dentista.

Professora, Programa de Pós-Graduação em Ciências da Saúde, UFRN. 


\section{Introdução}

A consolidação dos princípios doutrinários do Sistema Único de Saúde (SUS), definidos na Constituição Federativa de 1988 - universalidade, integralidade, eqüidade e participação social enfrenta desafios na prática de saúde. As características de iniqüidade e desigualdades sociais profundamente enraizadas na cultura brasileira (Brasil, 2006a), o paradigma do cuidado focado no corpo biológico (Luz, 2004; Capra, 1996) e as características do modelo da gestão do trabalho e dos serviços burocrático, autoritário, tecnoassistencial e desorganizado como rede de atendimento (Brasil, 2007) provocam crônica insatisfação em trabalhadores e usuários, freqüentemente exacerbada, e submete a risco sua legitimidade política e social (Feuerwerker, 2005).

Sabe-se que, embora tenhamos as garantias constitucionais e a consagração dos direitos humanos e universais, há grande distância entre a lei escrita e o cotidiano dos serviços de saúde (Gomes, Fraga, 2001). Em estudo realizado sobre a percepção do cliente hospitalizado acerca de seus direitos e deveres, foi observado o seu desconhecimento, trazendo o medo de exteriorizar sentimentos por temor de represália do profissional. Ressalta, ainda, a importância de estratégias junto aos profissionais que recobrem a cidadania e o respeito aos direitos (Veloso, Spindola, 2005).

Os direitos dos pacientes não são encontrados em código legal único (Timi, 2005), mas diversos documentos asseguram a dignidade ao ser humano no atendimento em saúde: Constituição Federal do Brasil, Código Civil Brasileiro, Código Penal Brasileiro, Código de Defesa do Consumidor, Estatuto da Criança e do Adolescente, Estatuto do Idoso, Lei dos Planos de Saúde e normas da Agência Nacional de Saúde Suplementar, códigos de ética das profissões, resoluções do Conselho Federal de Medicina, declarações internacionais de princípios, normas de pesquisa com seres humanos, normas do Ministério da Saúde, legislação esparsa e jurisprudência. O Ministério da Saúde publicou, em 1999, uma carta de direitos dos usuários, e, após sete anos, a Carta dos Direitos dos Usuários da Saúde (Brasil, 2006b).

É condição importante para o pleno exercício da cidadania que os pacientes tomem consciência de seus direitos e deveres, atuando de maneira a questionar a sua exeqüibilidade (Gauderer, 1998). À medida que há apropriação destes direitos, equilibrados com a apropriação de deveres, pelo paciente e família, torna-se possível maior controle social e a participação coletiva nas ações de atenção e nos processos da gestão. Esses valores de autonomia e co-responsabilidade integram a proposta de humanização na saúde, do Ministério da Saúde, entendida como a valorização dos diferentes sujeitos implicados na produção da saúde: usuários, trabalhadores e gestores (Brasil, 2006c) e o protagonismo nas decisões (Campos, 2005).

No intuito de fazer avançar a participação política e a visão crítica dos pacientes, visando à autonomia e ao direito do cidadão, a Carta dos Direitos dos Usuários da Saúde é um dos dispositivos da Política Nacional de Humanização da Atenção e da Gestão em Saúde (PNH) do Ministério da Saúde. Entende-se ser necessário garantir um atendimento humanizado, acolhedor e resolutivo para todos os usuários do SUS (Barros, Passos, 2005).

Apesar dos avanços, como os direitos reconhecidos na Constituição Federal e a regulação do SUS, o fortalecimento das instâncias de defesa dos direitos do consumidor, estes não foram suficientes para assegurar a legitimação do direito à saúde de todos os cidadãos usuários. À medida que dependem, em parte, da ação administrativa e política do Estado, que nem sempre afiança medidas de proteção a esses direitos, a sociedade é conduzida a criar espaços democráticos para a conquista do direito à saúde, sobretudo em sociedades autoritárias e desiguais como a brasileira (Chauí, 2006). A educação mostra-se como uma possibilidade de acesso à informação e consciência política em direção a uma mudança nas práticas de saúde que ferem a dignidade humana.

O Estado do Ceará, integrando o movimento nacional pela humanização, lançou, em 2003, a Política Estadual de Humanização da Atenção e da Gestão em Saúde do Ceará (PEH/CE) (Ceará, 2005a) e o Código dos Direitos do Paciente: carta dos direitos e deveres da pessoa hospitalizada no SUS/CE (Ceará, 2005b), inspirada nas concepções de Jaime e Carla Pinsky, na Introdução à magnífica História da Cidadania, por eles organizada: 
Ser cidadão é ter direito à vida, à liberdade, à propriedade, à igualdade perante a lei: é, em resumo, ter direitos civis. É também participar no destino da sociedade, votar, ser votado, ter direitos políticos. Os direitos civis e políticos não asseguram a democracia sem os direitos sociais, aqueles que garantem a participação do indivíduo na riqueza coletiva: à educação, ao trabalho, ao salário justo, à saúde, a uma velhice tranqüila. Exercer a cidadania é ter direitos civis, políticos e sociais. (Pinsky, Pinsky, 2003, p.8)

O texto do Código destaca o termo "pessoa", assim evitando o contencioso teórico entre paciente, cliente e usuário, bem como a inserção de ideologia de gênero. O presente escrito opta pelo vocábulo "paciente", pela sua emergência nas rotinas dos serviços e na naturalização das falas. Deste modo, é relevante a criação de formas de propagação das políticas de humanização e, sobretudo, o fortalecimento dos coletivos na discussão dos direitos de cidadania aplicados às realidades cotidianas.

A Carta dos Direitos e Deveres encerra uma história a ser contada. O governador Lúcio Alcântara, quando Secretário de Saúde, em 1992, teve uma idéia parecida. Chegou a publicar, no Diário Oficial (Ceará, 1992), uma resolução estabelecendo critérios e definindo direitos e deveres. Quando assumiu o Governo, em 2003, ele pediu ao Secretário, motivado pela política de humanização em saúde, para retomar o escrito. A análise do texto permitiu entender que ele apresentava um conteúdo muito bom, mas misturava direitos, deveres, princípios, justificativas, diretrizes, de modo tecnicamente inadequado.

Os princípios, as diretrizes e a justificativa integraram o texto da Política Estadual de Humanização da Atenção e da Gestão em Saúde do Ceará, e a redação da Carta concentrou, de modo objetivo, os direitos e os deveres. Em seguida, foi agregada a consulta a outros documentos: a Declaração de Lisboa (Assembléia Geral da Associação Médica Mundial, 1981), revista em Bali, em 1995 o capítulo sobre saúde da Constituição Brasileira (Brasil, 1988); o Documento-Base do Programa Nacional de Humanização da Assistência Hospitalar (PNHAH) (Brasil, 2002); um Manual da Ordem dos Advogados do Brasil, Secção Ceará (Ordem dos Advogados do Brasil, 2000); alguns livros e outros textos para fundamentação (Gomes et al., 2000; Sampaio, 2000). Sabe-se, porém, que a iniciativa e a aprovação dos governantes oferecem um salvo-conduto, um facilitador das ações, mas não adianta esta vontade, se a base que executa o trabalho - que está no front das guerrilhas do cotidiano, que se encontram na relação direta com os clientes - não se envolver com o projeto, não mudar de atitudes, não acreditar (Ceará, 2006).

Uma vanguarda, em certo momento histórico, pode conseguir a aprovação de uma lei, mas também cair no vazio, porque a maioria dos trabalhadores, exatamente os operadores dos cuidados, não se sente motivada ou sequer compreende a lei. Então, além do ineditismo, no Estado do Ceará, do lançamento do documento Direitos do Paciente: Carta dos Direitos e Deveres da Pessoa Hospitalizada no SUS (Ceará, 2005b), é necessário destacar o ineditismo da aplicação do método da roda de conversa à discussão desses direitos e deveres, com a finalidade de incluí-los na consciência e no quotidiano dos trabalhadores. Nesta perspectiva, o objetivo deste trabalho é apresentar as rodas de conversa sobre os direitos e deveres dos usuários do SUS no âmbito das unidades hospitalares.

\section{Metodologia}

Esta pesquisa, descritiva e exploratória, baseou-se nos princípios do Programa de Formação em Saúde e Trabalho (PFST) da PNH, que articula formação e pesquisa-intervenção em rede, visando ao diálogo-confrontação entre conhecimento científico e experiências dos trabalhadores: nucleação de trabalhadores, fazendo circular conceitos que permitem apreender a complexidade dos direitos; produção de saberes e problematização dos modos da gestão em curso para alterar as práticas de desrespeito dos direitos; estímulo aos projetos e planos coletivos em defesa da dignidade humana; fortalecimento dos trabalhos intersetoriais e multiprofissionais que possam compreender/transformar a realidade das práticas cotidianas, ampliando a capacidade normativa dos trabalhadores (Barros, Mori, Bastos, 2006). 
Levando-se em conta suas características de fomentar a inclusão, a participação, o espaço democrático de aprendizagem e a informalidade, escolhemos a roda de conversa como estratégia pedagógica para trilhar o caminho metodológico, com vistas a disseminar o Código com trabalhadores, que se tornariam, posteriormente, multiplicadores de outras rodas, em se sentindo totalmente à vontade, no ambiente hospitalar. Isto porque a discussão exige cada um vendo o outro, para congregar e incorporar modos dinâmicos e críticos de reflexão sobre as próprias práticas.

A implementação das rodas foi realizada no período de abril a junho de 2005, em dois hospitais, um público e outro contratado, localizados em Fortaleza, Ceará. Foram promovidas, portanto, três rodas de conversa, nos dois hospitais, interdisciplinar e intersetorial, compreendendo 40 trabalhadores, com a seguinte composição: médicos, assistentes sociais, enfermeiros, auxiliares administrativos, técnicos de Enfermagem, farmacêuticos, engenheiros, operadores de serviços gerais, fisioterapeutas, psicólogos, nutricionistas e administradores. Alguns destes profissionais exerciam funções de chefia, diretoria, ouvidoria ou eram membros de Grupo de Trabalho de Humanização (GTH). A roda de um dos hospitais contou, ainda, com a presença de representante do movimento social dos portadores de síndrome de imunodeficiência adquirida. Priorizou-se a participação dos profissionais pela necessidade de refletir com eles novas atitudes e possibilidades para disseminação dos direitos do paciente nos hospitais. Os usuários dos serviços seriam incluídos nas rodas subseqüentes, facilitadas pelos multiplicadores formados.

Assim, procurou-se praticar a Carta dos Direitos no dia-a-dia dos hospitais. Qual é a consciência que os trabalhadores de saúde têm sobre os direitos dos hospitalizados? Quais as atitudes que os trabalhadores precisam mudar, neles próprios, para a garantia prática destes direitos? Quais as condições que os gestores de saúde necessitam programar para a garantia prática destes direitos? Estas foram as perguntas lançadas à roda dos trabalhadores, em todo o círculo da discussão.

Quem conduz o processo é visto como facilitador, participante de um diálogo, que parte da vivência e dos saberes de cada um, promovendo a problematização, em busca de informação para a reflexão e o discernimento informado para a ação. Os atos de ensinar e aprender são uma unidade inseparável (Freire, 2004), possibilitando mão dupla e o compartilhamento de saberes e práticas. Dos três círculos realizados, registrou-se uma duração de 150 minutos. As participações foram gravadas, com o consentimento dos grupos, para transcrição. O material dessas transcrições foi sistematizado em documento da Secretaria da Saúde do Estado do Ceará (SESA/CE) (Ceará, 2006) e fundamenta o presente artigo. As transcrições organizadas tiveram seus resultados ordenados segundo a técnica de Análise de Conteúdo (Bardin, 2002). Foram seguidos os princípios da Resolução 196/96, do Conselho Nacional de Saúde, que dispõe sobre pesquisas com seres humanos (Brasil, 2001). O projeto foi submetido e aprovado pelo Comitê de Ética em Pesquisa da Universidade Estadual do Ceará, sob o protocolo n 04185929-4.

\section{Desenvolvimento da experiência}

\section{A política estadual de humanização e os direitos do paciente}

Em 2000, foi instituído o PNHAH, focado nos hospitais e na criação dos GTH. Esse processo durou três anos e evoluiu por etapas, com o Ceará realizando um estudo-piloto no Hospital Geral Dr. César Cals (HGCC) e, em seguida, a primeira fase, envolvendo seis hospitais. A segunda etapa, prevista para o final de 2002, com trinta hospitais, foi truncada pelo processo político-eleitoral, para a Presidência da República e para o Governo do Estado.

No início do primeiro governo Lula, o Ministério da Saúde submeteu o PNHAH a uma grande revisão e criou a Política Nacional de Humanização na Atenção e Gestão em Saúde (PNH). O foco em hospital evoluiu para a rede de cuidados; o fulcro na assistência derivou para a atenção integrada com a gestão, e a lógica vertical de programa cresceu para a lógica transversal de política. O desafio ampliou-se: emergência, Unidade de Tratamento Intensivo (UTI), saúde da família, saúde indígena, saúde do trabalhador, saúde mental. Não era possível abandonar o hospital, e muitas técnicas do PNHAH, como o GTH e as cartas de direito, tiveram seguimento. Grande tarefa foi envolver os municípios das capitais e das macrorregiões de saúde, no esforço geral de humanização em saúde, sobretudo na atenção 
primária. A Secretaria de Saúde do Estado do Ceará decidiu que o debate da Carta de Direitos e a implantação dos GTH fariam avançar o trabalho da humanização em saúde nos hospitais.

Os GTH do Hospital Geral Waldemar de Alcântara (HGWA) e do Hospital São José (HSJ) candidataram-se a avançar na discussão da Carta de Direitos. O consultor da PNH para os Estados do Ceará, Piauí e Maranhão e a coordenadora da Comissão Estadual de Humanização da Atenção e da Gestão em Saúde do Ceará responsabilizaram-se pela mediação das rodas, de forma que a experiência e os conhecimentos ficassem com os trabalhadores, para fins de multiplicação.

\section{A roda de conversa como estratégia pedagógica}

A roda de conversa é uma estratégia educativa e comunicativa cuja finalidade é a satisfação das necessidades básicas de aprendizagem, compreensão e empowerment. Esta técnica, no presente ensaio, baseou-se na proposição desenvolvida nos trabalhos de Simonetti, Adrião e Cavasin (2007, p.247), para quem "é um espaço destinado ao diálogo, comunicação e troca de informações [...] as pessoas têm a oportunidade de adquirir capacidade de discernimento, de modo que provoque a mudança de comportamento e uma maior autonomia". A meta principal é permitir a livre expressão de dúvidas, vivências e acontecimentos de vida.

A proposta fundamentou-se ainda no Método da Roda, desenvolvido por Campos (2000, p.68), em cuja idéia se "pensa a constituição do Sujeito e dos Coletivos em função de Planos situados entre o seu mundo interno e as suas circunstâncias - mundo externo", e no pensamento de Freire (2004, p.23), ao incutir a noção de que "quem ensina aprende ao ensinar e quem aprende ensina ao aprender".

No contexto do estudo, aplicou-se a formulação intelectiva e afetiva dos direitos e deveres do paciente hospitalar, pelos membros da comunidade de trabalhadores do hospital, mediante uma participação ativa e efetiva. Na qualidade de estratégia pedagógica, foi capaz de promover a reflexão, o compartilhar de experiências vividas e questões práticas (Simonetti, Adrião, Cavasin, 2007).

A lógica baseada no respeito aos conhecimentos e experiências dos participantes centrou-se na valorização do sujeito e da conversação, proporcionando troca de idéias entre os trabalhadores, para que todos se apoderassem das razões e das teorias por trás de cada direito ou dever. A estratégia tinha suporte no reconhecimento de valores e aprendizagens anteriores, que serviram de base para a constituição de novas aprendizagens e para a tomada de decisões no sentido de adequar a realidade existente aos direitos da pessoa hospitalizada.

A discussão do Código baseou-se na noção de que cada artigo remete a uma teoria. Refletiu-se sobre o que é Direito, qual é a natureza deste Direito e os diferentes ramos do Direito. Depois disso, buscava-se a compreensão do que existe em torno do Direito, como é que ele causa impacto no serviço e, por último, problematizavam-se a atitude do trabalhador e a condição que o hospital deveria oferecer para torná-lo realidade. Cada artigo do Código remetia para seis ordens temáticas: uma técnica, jurídica, psicológica e antropológica; outra relacional, sobre as interfaces dos artigos e de um direito com outro; e, por último, uma política, destacando os efeitos na prática do trabalhador. Algumas dessas problemáticas têm raízes nas condições de trabalho e de vida, outras nas atitudes, que são responsabilidades que o trabalhador precisa desenvolver. Não basta a informação para mudar o modo de agir. Atitude é algo mais delicado de se transformar. O código é composto de 35 direitos e dez deveres, sendo destacadas as discussões dos artigos cinco e 13 como exemplos neste ensaio.

\section{Resultados analíticos: a voz dos trabalhadores}

As normas do serviço de saúde e protocolos repetitivos ao longo dos anos, sem função justificável no presente, foram questionadas pelos trabalhadores. A possibilidade de reinvenção dessas normas, tornando o trabalho inventivo, foi discutida. Foucault (1999) assinala que só há poder com resistência, pois, ela, em primeiro lugar, subverte, faz reviravolta e escapa aos controles, possibilitando novas formas de vida e trabalho. Essa perspectiva dos trabalhadores de trazer à baila o que se torna rotina, permitiu repensar possibilidades de mudanças concretas, destinadas à garantia dos direitos do paciente com suporte nos principais aspectos trazidos ao debate interdisciplinar. 
Segundo Campos (2000), é necessário considerar a tensão dialética entre controle externo e autonomia dos sujeitos, pois o ser humano é imerso na história e na sociedade, mas nem por isso desprovido de uma subjetividade e de capacidades para se posicionar ante os desafios de sua conjuntura.

Um exemplo de texto formulado coletivamente é destacado no artigo cinco, que trata do direito do paciente ser identificado pelo nome e sobrenome. Uma trabalhadora abre o debate:

\begin{abstract}
Essa é uma questão clara para mim, mas não sei explicar. Eu vejo, na Pediatria, as pessoas chamarem todas as mães mãezinha pra lá, mãezinha pra cá. Isso pra mim torna-se tão pejorativo, não soa bem. Não sei o porquê, mas me incomoda profundamente. $\mathrm{O}$ diminutivo é até afetuoso, em muitas ocasiões, mas aqui parece infantilizador. (Trabalhadora do hospital)
\end{abstract}

Em seguida, os facilitadores comentaram: "mãezinha" é uma forma genérica, refere-se a uma categoria abstrata. Tem a maternidade precoce de quem pariu aos 12 anos; a maternidade tardia de quem pariu aos 45 anos; quem engravidou dentro de uma relação estável, amorosa; e quem está sozinha, por escolha ou por abandono; quem está saudável e quem tem doença associada, quem é pobre e quem é rica. Além do mais, tem a singularidade de cada sujeito. Parece, no entanto, ser mais fácil chamar "mãezinha" do que perguntar e aprender o nome, criar um vínculo. Também é preciso incluir o pai acompanhante. Outros dois profissionais expõem seu dilema e a necessidade de modificar a atitude:

É verdade. Tem homem ficando na enfermaria. Vai fazer o que? Vai chamar o pai de "mãezinha"? Não é mãe, nem pai, nem irmão, nem irmã, nem tia. São pessoas que têm nomes. A presença do acompanhante e do homem nos obriga a mudar muita coisa dos nossos comportamentos. (Trabalhador do hospital)

O paciente também é chamado de "bebê": "Vem cá, meu bebê!". Ou então, grosseiramente, "Ei, você aí". Às vezes tem apelido que a pessoa gosta, olha o Pelé, olha o Lula, mas outros a pessoa detesta. Não pode ficar chamando aquele "viadinho" ou "neguinho" ou "lôra". Nada disso deve ser usado. Estes tratamentos podem até criar vínculo, mas negativo, preconceituoso, desrespeitoso. Tem gente que acha que a maneira de ser gentil é incluir na própria família e passa a chamar todo mundo de "tio", de "tia". (Trabalhador do hospital)

Centrados nas discussões, os facilitadores retomaram o diálogo com uma nova explanação: o que precisamos fazer é perguntar para a pessoa o nome dela e como é que ela gosta de ser chamada. O relacionamento deve obedecer, então, à referência que é dada pela própria pessoa.

Em muitas situações cotidianas, de acordo com Fortes (2004), os profissionais assumem, em nome de "fazer o bem", atitudes paternalistas e autoritárias que já não percebem, contrárias à vontade autônoma dos cidadãos e violando seus direitos.

O compartilhamento na roda também pode ser verificado na conversa sobre o artigo 13, que aborda o direito à proteção da exposição corporal e da vergonha, garantida a realização de exames em ambientes que preservem seu pudor. Um trabalhador da área administrativa e uma enfermeira destacam a importância, para o paciente, sobre o cuidado com sua intimidade:

Nós fazemos pesquisa de satisfação do usuário e nós tínhamos um percentual significativo de insatisfação. Fomos abrir a questão e descobrimos: "preservar a intimidade". Era o problema da vestimenta do hospital, sem uso de roupa de baixo e aberta nas costas, mostrando as nádegas, quando o paciente caminha. (Trabalhador do hospital)

Tivemos uma paciente que vivia com um seio de fora, porque a roupa era número bem menor que o dela. Ela reclamava e ninguém atendia..., diziam que faltava roupa. Uma vez encontrei uma senhora jovem fazendo uso da aparadeira e sem o biombo de proteção. 
Estava faltando biombo. É muito comum a gente vê na UTI as pessoas com o corpo à mostra, seminus, usando aqueles eletrodos, aqueles fios, e sem cortina, pelo motivo do calor. Eu chamo os auxiliares de enfermagem e reclamo: "olha aí...vamos cuidar... vamos proteger". (Trabalhadora do hospital)

Os facilitadores explicam, com respaldo na temática exposta pelos trabalhadores: há sempre um jeito de fazer isso, sem grandes tecnologias ou altos custos. É preciso mobilizar a sensibilidade para perceber e a criatividade a fim de resolver. É muito interessante refletir como nos sentiríamos em situação semelhante, fazendo o jogo da troca de papel, ou do espelho, técnicas que o psicodrama, por exemplo, nos oferece para vivermos a alteridade. As questões referentes a vestimentas trazem à tona o compromisso da gestão em criar condições para o respeito à intimidade do paciente.

Além das questões da gestão e relacionamento, entretanto, o incremento de ações humanizadoras, para melhor atingir seus objetivos, deve considerar o princípio da humanidade, segundo o qual o homem se torna o centro da ação ética, e não somente meio de satisfação dos interesses das forças sociais atuantes na atenção em saúde (Fortes, 2004). Neste arcabouço, devem estar humanização e direitos do paciente no seio das políticas e programas de saúde (Vaitsman, Andrade, 2005).

Outra temática comentada pelos profissionais foi a de como educar o paciente e a família nos direitos e deveres, numa clara noção de que essa função social também envolve a participação popular: "Como que a gente vai educar também o nosso paciente dos direitos dele? Eu acho que é mais delicado do que esclarecer o profissional. É um grande desafio que a gente vai enfrentar ao longo do processo" (Trabalhador do hospital). Demonstra, ainda, a conscientização do profissional acerca da importância dos direitos do paciente. A resposta a essa questão é encetada por outro profissional, que diz:

\begin{abstract}
A questão básica é a da pedagogia do encontro. Cada vez que o profissional explica algo, está educando nos direitos. É no dia a dia que os profissionais podem estar fazendo isso, se tiverem incorporado a atitude. Por que todo ato sanitário, implica numa dimensão de educação. Precisa divulgar pela mídia, informar coletivamente, pedir para o PSF fazer grupo nas comunidades dizendo da existência da Carta de Direitos e Deveres, mas é preciso o exemplo quotidiano, a prática do exemplo. (Trabalhador do hospital)
\end{abstract}

Os facilitadores discutiram a importância do papel do profissional como educador na prática sanitária: a todo momento em que o profissional da saúde se relaciona com o paciente, ele está ensinando e aprendendo. E, na maioria das vezes, está ensinando errado, ao permitir que o paciente invente um conhecimento em cima de seus silêncios. É fundamental, portanto, que este trabalho educativo se estenda aos pacientes, visando a sua conscientização sobre a desigualdade e violações de seus direitos, fortalecendo o controle social e a luta contra as iniqüidades sociais e o desrespeito aos direitos humanos.

Para os participantes, no tocante à vivência do encontro coletivo, o principal aspecto ressaltado foi que a roda possibilitou "ficar atento à vivência do profissional de saúde". Em um contexto marcado pela urgência e necessidade de decisões racionais e instrumentais, o profissional, em raros momentos, é conduzido a refletir o seu fazer cotidiano, o que permite ampliar a capacidade de partilhar dilemas comuns, reavendo o senso de grupo.

As rodas foram consideradas um "despertar", "uma discussão que amplia a visão da gente", pois promoveram uma "reflexão profunda", permitindo "resgatar a pessoa escondida dentro da patologia". Como conseqüência da participação nas rodas, um participante referiu que "as pessoas que tiveram a honra de participar, cresceram e muito, pois a roda trouxe um embasamento muito grande para todos".

\title{
Considerações finais
}

Ampliar a consciência dos direitos dos usuários na prática dos serviços requer um trabalho educativo que envolva gestores, trabalhadores e usuários. Isso porque a garantia constitucional e os códigos legitimados não são suficientes para efetivar esses direitos na prática. 
A proposta da discussão da Carta de Direitos do Paciente em rodas de conversa - objetivando entender a história, os motivos da elaboração textual, e avaliar o impacto do dispositivo, ou seja, o que cada hospital precisa fazer para cumprir essas garantias, em termos de condições de funcionamento e atitude dos profissionais - mostrou-se um caminho promissor para provocar mudanças nos ambientes de saúde. O compartilhar de experiências possibilitou maior internalização pela ponte criada entre 0 discurso e a realidade.

O desafio de formar multiplicadores nos direitos do paciente é um imperativo no cotidiano, visto que a atenção e a gestão humanizadas em saúde somente serão efetivadas pela dignidade conquistada e pelo acolhimento promovido nas relações entre todos os agentes desta cena pública. O Código, na roda de conversa, revelou-se importante instrumento de avaliação do estado de humanização do cuidado hospitalar e da educação para a cidadania dos trabalhadores. Fez refletir as relações e as condições de funcionamento dos serviços, fornecendo meios para instigar mudanças. A roda de conversa promoveu a "grupalidade" estimulada pela força do coletivo, que potencializa um pensamento não solitário, mas solidário, de um novo modo de promover saúde, pela instância da ética cidadã e humanitária.

\section{Colaboradores}

Annatália Meneses de Amorim Gomes elaborou a pesquisa, conduziu as rodas de conversa, construiu o artigo, efetuou as revisões e preparou o envio para a revista. José Jackson Coelho Sampaio elaborou a pesquisa, conduziu as rodas de conversa, construiu o artigo e efetuou as revisões. Maria das Graças Barreto de Carvalho participou nas rodas de conversa, discutiu aspectos do texto e contribuiu na análise dos dados. Marilyn Kay Nations participou nas rodas de conversa, contribuiu na organização, análise e discussão dos resultados. Maria Socorro Costa Feitosa Alves construiu o artigo, colaborou na análise e discussão dos dados e participou nas revisões.

\section{Referências}

ASSEMBLÉIA GERAL DA ASSOCIAÇÃO MÉDICA MUNDIAL. Declaração de Lisboa: sobre os direitos do paciente. 1981. Disponível em: <http://www.dhnet.org.br/ direitos/codetica/medica/14lisboa.html>. Acesso em: 12 jul. 2003.

BARDIN, L. Análise de conteúdo. Lisboa: Edições 70, 2002.

BARROS, M.E.B.; MORI, M.E.; BASTOS, S.S. O desafio da Política Nacional de Humanização nos processos de trabalho: o instrumento "Programa de Formação em Saúde e Trabalho". Cad. Saúde Coletiva, v.14, n.1, p.31-48, 2006.

BARROS, R.B.; PASSOS, E. Humanização na saúde: um novo modismo? Interface Comunic., Saúde, Educ., v.9, n.17, p.389-94, 2005.

BRASIL. Conselho Nacional de Secretários de Saúde. SUS: avanços e desafios. 2.ed. Brasília: CONASS, 2007.

Comissão Nacional sobre Determinantes Sociais da Saúde. Iniqüidades em saúde no Brasil: nossa mais grave doença. Documento apresentado por ocasião do lançamento da Comissão Nacional sobre Determinantes Sociais da Saúde - CNDSS. Rio de Janeiro: CNDSS, 2006a. 
BRASIL. Ministério da Saúde. Carta dos direitos dos usuários da saúde. Brasília: 2006b.

. Ministério da Saúde. Secretaria Executiva, Núcleo Técnico da Política Nacional de Humanização. Política Nacional de Humanização: HUMANIZASUS: documentobase para gestores e trabalhadores do SUS. Brasília: PNH, 2006c.

Ministério da Saúde. Manual do Programa Nacional de Humanização da Assistência Hospitalar - PNHAH. Brasília: PNHAH, 2002.

Ministério da Saúde. Conselho Nacional de Saúde. Resolução 196/96. Brasília: CNS, 2001.

Constituição da República Federativa do Brasil. Seção II da Saúde. 1988. Disponível em: <http://www.planalto.gov.br/ccivil_03/constituicao/ constitui\% C3\% A7ao.htm>. Acesso em: 23 mai. 2006.

CAMPOS, G.W.S. Humanização na saúde: um projeto em defesa da vida? Interface Comunic., Saúde, Educ., v.9, n.17, p.398-403, 2005.

Um método para análise e co-gestão de coletivos: a constituição do sujeito, a produção de valor de uso e a democracia em instituições: o método da roda. São Paulo: Hucitec, 2000.

CAPRA, F. O ponto de mutação. São Paulo: Círculo do Livro, 1996.

CEARÁ. Secretaria da Saúde do Estado do Ceará. Código dos direitos dos pacientes: reflexões a partir do cotidiano hospitalar. Fortaleza, 2006.

Secretaria da Saúde do Estado do Ceará. Política estadual de humanização da atenção e gestão em saúde do Ceará. Fortaleza, 2005a.

Secretaria da Saúde do Estado do Ceará. Código dos direitos do paciente: carta dos direitos e deveres da pessoa hospitalizada no Sistema Único de Saúde/SUS. Fortaleza, 2005b.

Secretaria da Saúde do Estado do Ceará. Portaria n. 229, de 15 de maio de 1992. Estabelece os direitos, os deveres e as responsabilidades do usuário do Sistema Único de Saúde - SUS e dá outras providências. Fortaleza: Secretaria da Saúde do Estado do Ceará, 1992.

CHAUÍ, M. Marilena. Chauí diz que Brasil convive com violência estrutural e ataca a "oligarquia". In: FÓRUM DE ENTIDADES NACIONAIS DE DIREITOS HUMANOS, 2006. Anais... [S.I.], 2006. Disponível em: <http://www.direitos.org.br/ index 2 .php?option $=$ com_content\&do_pdf $=1 \& i d=1749 \% 20->$. Acesso em: 10 out. 2006.

FEUERWERKER, L. Modelos tecnoassistenciais, gestão e organização do trabalho em saúde: nada é indiferente no processo de luta para a consolidação do SUS. Interface Comunic., Saúde, Educ., v.9, n.18, p.489-506, 2005.

FORTES, P.A.C. Ética, direitos dos usuários e política de humanização da atenção à saúde. Saúde Soc., v.13, n.3, p.30-5, 2004.

FOUCAULT, M. Em defesa da sociedade: curso no Collège de France (1975-1976). Trad. Maria Ermantina Galvão. São Paulo: Martins Fontes, 1999.

FREIRE, P. Pedagogia da autonomia: saberes necessários à prática educativa. 28.ed. São Paulo: Paz e Terra, 2004.

GAUDERER, E.C. Os direitos do paciente: um manual de sobrevivência. 6.ed. Rio de Janeiro: Record, 1998.

GOMES, A.M.A. et al. Direitos e deveres dos usuários: uma contribuição à SESA-CE na construção destes direitos. Fortaleza: Secretaria de Saúde do Estado do Ceará, 2000. 
GOMES, I.L.V.; FRAGA, M.N.O. Direitos do cidadão hospitalizado: teoria e práxis. Fortaleza: Ban Gráfica, 2001.

LUZ, M.T. Natural, racional, social: razão médica e racionalidade científica moderna. São Paulo: Hucitec, 2004

ORDEM DOS ADVOGADOS DO BRASIL. Manual dos direitos do paciente. Fortaleza, 2000 .

PINSKY, J.; PINSKY, C. (Orgs.). História da cidadania. São Paulo: Objetiva, 2003.

SAMPAIO, J.J.C. Saúde e educação: serviços à humanidade. Fortaleza: Universidade Estadual do Ceará, 2000.

SÃO PAULO. Lei n. 10.241, de 17 de março de 1999. Dispõe sobre os direitos dos usuários dos serviços e das ações de saúde no Estado e dá outras providências. Diário Oficial [do] Estado de São Paulo, v.109, n.51, 18 mar. 1999. Seção 1, p.1.

SIMONETTI, J.R.; ADRIÃO, M.; CAVASIN, S. Saúde sexual e reprodutiva: uma experiência de rodas de conversa em Corumbá - Mato Grosso e Foz do Iguaçu - Paraná. In: BRASIL. Ministério da Saúde. Escolas promotoras de saúde: experiências do Brasil. Brasília, 2007. p.247-52.

TIMI, J.R.R. Direitos do paciente. Rio de Janeiro: Revinter, 2005.

VAITSMAN, J.; ANDRADE, G.R.B. Satisfação e responsividade: formas de medir a qualidade e a humanização da assistência à saúde. Ciênc. Saúde Coletiva, v.10, n.3, p.599-613, 2005.

VELOSO, R.C.; SPINDOLA, T. A percepção do cliente hospitalizado acerca de seus direitos e deveres. Rev. Enferm. UERJ, v.13, n.1, p.38-43, 2005.

GOMES, A.M.A. et al. Código de los derechos y deberes de La persona hospitalizada em Le Sistema Único de Salud brasileño (SUS): el cotidiano hospitalario en conversaciones conjuntas. Interface - Comunic., Saúde, Educ., v.12, n.27, p.773-82, out./dez. 2008.

Los derechos de los pacientes consisten en dispositivo para modificar la atención en la gestión del SUS. El objeto de este trabajo es el de presentar ruedas de conversación sobre los derechos y deberes de los usuarios del SUS en el ámbito de las unidades hospitalarias. Se trata de un estudio descriptivo y exploratorio realizado en dos hospitales de Fortaleza, estado de Ceará, Brasil. Se organizaron, en cada servicio, tres ruedas de conversación con 40 trabajadores de varias profesiones y sectores. Se utilizó para el debate el Código de Derechos y Deberes del Paciente en el SUS de Ceará. Los discursos se analizaron según el Análisis de Contenido de acuerdo con Lawrence Bardin. Se verificó que las normas dificultan la efectivación de los derechos. Se amplió la visión crítica y el discernimiento; revelándose un importante instrumento de educación para la ciudadanía.

Palabras clave: Derechos del paciente. Humanización de atención. Educación en salud. 